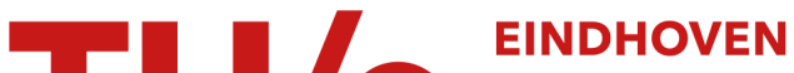 UNIVERSITY OF TECHNOLOGY
}

\section{Clinical outcomes after cataract surgery with a new transitional toric intraocular lens}

Citation for published version (APA):

Ferreira, T. B., Berendschot, T. T. J. M., \& Ribeiro, F. J. (2016). Clinical outcomes after cataract surgery with a new transitional toric intraocular lens. Journal of Refractive Surgery, 32(7), 452-459.

https://doi.org/10.3928/1081597X-20160428-07

\section{Document license:}

TAVERNE

DOI:

10.3928/1081597X-20160428-07

Document status and date:

Published: 01/07/2016

\section{Document Version:}

Publisher's PDF, also known as Version of Record (includes final page, issue and volume numbers)

\section{Please check the document version of this publication:}

- A submitted manuscript is the version of the article upon submission and before peer-review. There can be important differences between the submitted version and the official published version of record. People interested in the research are advised to contact the author for the final version of the publication, or visit the $\mathrm{DOI}$ to the publisher's website.

- The final author version and the galley proof are versions of the publication after peer review.

- The final published version features the final layout of the paper including the volume, issue and page numbers.

Link to publication

\section{General rights}

Copyright and moral rights for the publications made accessible in the public portal are retained by the authors and/or other copyright owners and it is a condition of accessing publications that users recognise and abide by the legal requirements associated with these rights.

- Users may download and print one copy of any publication from the public portal for the purpose of private study or research.

- You may not further distribute the material or use it for any profit-making activity or commercial gain

- You may freely distribute the URL identifying the publication in the public portal.

If the publication is distributed under the terms of Article $25 \mathrm{fa}$ of the Dutch Copyright Act, indicated by the "Taverne" license above, please follow below link for the End User Agreement:

www.tue.nl/taverne

Take down policy

If you believe that this document breaches copyright please contact us at:

openaccess@tue.nl

providing details and we will investigate your claim. 


\title{
Clinical Outcomes After Cataract Surgery With a New Transitional Toric Intraocular Lens
}

\author{
Tiago B. Ferreira, MD; Tos T.J.M. Berendschot, PhD; Filomena J. Ribeiro, MD, PhD, FEBO
}

\section{ABSTRACT}

PURPOSE: To evaluate the visual outcomes of patients who underwent cataract surgery with implantation of a transitional toric monofocal intraocular lens (IOL) (Precizon Toric IOL, model 565; Ophtec BV, Groningen, The Netherlands).

METHODS: In this prospective case series, 51 eyes of 39 patients with cataract and regular keratometric astigmatism between 1.00 and 4.50 diopters (D) that had phacoemulsification with implantation of a Precizon Toric IOL were included. Over a 4-month follow-up period, the main outcome measures were uncorrected and corrected distance visual acuities (UDVA and CDVA, respectively), spherical equivalent (SE) refraction, astigmatism outcomes evaluated according to the Alpins method, the IOL's rotational stability, and higher order aberrations.

RESULTS: At the 4-month follow-up visit, mean UDVA was $0.06 \pm 0.1$ logMAR (range: 0.4 to -0.18 logMAR) $(P<.001)$ and mean CDVA was $-0.00 \pm 0.07$ logMAR (range: 0.15 to -0.18 logMAR) $(P<.001)$. UDVA was 0.3 logMAR or better in 50 (98\%) eyes and 0.1 logMAR or better in $42(82 \%)$ eyes. Mean SE refraction was -0.19 $\pm 0.38 \mathrm{D}$ (range: -1.13 to $+0.50 \mathrm{D})$, with $44(86 \%)$ eyes within $\pm 0.50 \mathrm{D}$ of the attempted correction. Mean target induced astigmatism was $1.96 \pm 0.94 \mathrm{D}$ (range: 0.70 to $4.50 \mathrm{D}$ ) and mean surgically induced astigmatism was $1.85 \pm 1.01 \mathrm{D}$ (range: 0.07 to $4.64 \mathrm{D}$ ). Mean correction index was 0.87 (range: 0.07 to $2.29 \mathrm{D}$ ). Mean toric IOL axis rotation was $1.98^{\circ} \pm 1.78^{\circ}$ (range: $0^{\circ}$ to $\left.7^{\circ}\right)$. Ocular aberrometry was within normal values.

CONCLUSIONS: The implantation of the Precizon Toric IOL in patients with cataract and corneal astigmatism provided excellent visual outcomes, predictability of refractive results, rotational stability, and good optical performance.

[J Refract Surg. 2016;32(7):452-458.]

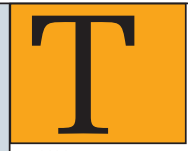

he aim of modern cataract surgery is not only to improve visual acuity, but also to achieve emmetropia and thus optimum uncorrected visual acuity. However, $20 \%$ to $30 \%$ of patients have preexisting corneal astigmatism of 1.25 diopters (D) or greater and approximately $10 \%$ have $2.00 \mathrm{D}$ or greater. ${ }^{1-3}$ Recent investigations suggest that the correction of astigmatism greater than $0.50 \mathrm{D}$, but not lower, can improve visual outcomes, so adequate astigmatic correction should be considered in patients with cataract. ${ }^{4}$

The Precizon Toric IOL (Precizon Toric IOL, model 565; Ophtec BV, Groningen, The Netherlands) has been designed with features to prevent postoperative rotation. The IOL's material and offset-shaped haptics are designed to improve adherence to the posterior capsule, preventing rotation and posterior capsule opacification. ${ }^{5-7}$ The optic surface has a new transitional conic design in which the dioptric power is calculated individually as a spherical aberration-free dioptric power. The main meridians and all meridians in between each have a different Coddington shape factor (transitional conic) and a different asphericity that is related to the Coddington shape factor of the respective meridian in accordance with a relationship providing an aberration-neutral refraction for the respective meridian. With the use of the Coddington shape factor, the lens can be optimized to minimize spherical aberrations (Figure A, available in the online version of this article). An aberration-neutral lens is obtained in which the effective dioptric power is constant along each meridian from the optic axis to the periphery of the lens and the amount of aberrations varies little with pupillary aperture. This transitional conic surface blends into the aspheric surface of all meridians, leading

From Hospital da Luz, Lisbon, Portugal (TBF, FJR); and University Eye Clinic Maastricht, Maastricht, The Netherlands (TTJMB).

Submitted: September 9, 2015; Accepted: February 15, 2016

Supported by a grant from Ophtec BV, Groningen, The Netherlands.

The authors have no financial or proprietary interest in the materials presented herein.

Correspondence: Tiago B. Ferreira, MD, Hospital da Luz, Serviço de Oftalmologia, Avenida Lusiada 100, 1500-650 Lisbon, Portugal. E-mail: tlcferreira@gmail.com

doi:10.3928/1081597X-20160428-07 
to a broader toric surface that could be more tolerant to rotation, misalignment, tilt, and decentration (Figure B, available in the online version of this article).

The purpose of this study was to evaluate the optical performance of a new monofocal toric IOL in patients with cataract and regular astigmatism.

\section{PATIENTS AND METHODS}

\section{Patient population}

This prospective interventional case series was performed in two clinical sites in Lisbon, Portugal (Egas Moniz Hospital and Luz Hospital). The study was conducted in accordance with the tenets of the Declaration of Helsinki and approved by each center's institutional review board. All patients provided written informed consent.

Inclusion criteria were clinically significant cataract, preexisting regular corneal astigmatism between 1.00 and $4.50 \mathrm{D}$ at the corneal plane, and expected visual acuity of 0.1 logMAR or better. Exclusion criteria were corneal pathology (eg, irregular astigmatism, previous surgery, or trauma), pathology that could limit visual acuity after surgery (eg, amblyopia, glaucoma, or retinal disease), and pathology that could compromise IOL stability or function (eg, pseudoexfoliation syndrome or small pupils limiting the ability to see the IOL reference markings).

\section{IOL}

The study IOL was the Precizon Toric model 565 monofocal toric one-piece IOL. The IOL is made of $25 \%$ hydrophilic acrylic material with an ultraviolet cut-off wavelength at $360 \mathrm{~nm}$ at which the transmission is below $10 \%$. The overall diameter is $12.5 \mathrm{~mm}$ and the optic diameter is $6 \mathrm{~mm}$. The haptics are modified Cshaped loops with $0^{\circ}$ angulation. The refractive index is 1.46 and the optic surface is aspheric. The benefits of aspheric IOLs include higher retinal image quality and contrast sensitivity. ${ }^{8}$ At the time of the study, the IOL was available with spherical equivalent (SE) powers of +10.00 to $+30.00 \mathrm{D}$ in $0.50-\mathrm{D}$ increments and cylindrical powers of +1.00 to $+6.00 \mathrm{D}$ in 0.50 - $\mathrm{D}$ increments.

\section{Preoperative Assessment}

Preoperatively, all patients had a full ophthalmologic examination including uncorrected (UDVA) and corrected (CDVA) distance visual acuities using $\log$ MAR acuity charts at a test distance of $4 \mathrm{~m}$ under photopic conditions $\left(85 \mathrm{~cd} / \mathrm{m}^{2}\right)$, manifest refraction, slit-lamp biomicroscopy, Goldmann applanation tonometry, and funduscopy under mydriasis.

The IOL power was calculated using the Hoffer $\mathrm{Q}^{9}$ formula if the axial length was shorter than $22 \mathrm{~mm}$ or the
SRK/T $\mathrm{T}^{10}$ if the axial length was $22 \mathrm{~mm}$ or longer. The Aconstant was 118.5. The refractive goal was emmetropia. Axial length and keratometry values were obtained using the IOLMaster partial coherence interferometry (Carl Zeiss Meditec AG, Jena, Germany). Corneal topography (Pentacam HR; Oculus Optikgeräte GmbH, Wetzlar, Germany) was performed to confirm the regularity of the astigmatism. The IOL cylinder power and axis placement were calculated using the online Precizon Toric Calculator (http://calculator.ophtec.com/login/classic-login, used between October 2014 and June 2015). Surgically induced astigmatism (SIA) was assumed to be $0.30 \mathrm{D}$ for a temporal clear corneal incision.

\section{SURGICAL TECHNIQUE}

Two experienced surgeons (TBF, FJR) performed all surgeries under topical anesthesia using a microcoaxial phacoemulsification technique with a 2.2-mm clear cornea incision. With the patient seated to prevent cyclotorsion, the previously calculated implantation axis was marked using a Neuhann-Nuijts one-step bubble marker (ASICO, Westmont, IL). The IOL was implanted using a disposable DualTec IOL injector (Ophtec BV). After IOL implantation and complete aspiration of the viscosurgical device anterior and posterior to the IOL, the IOL was rotated to its final position by aligning the corneal marks with the reference marks in the IOL.

\section{Postoperative Assessment}

Postoperative examinations were performed at day 1 , month 1, and month 4 using the same tests as for the preoperative examination. At the 4-month visit, ocular aberrometry was performed with the OPD-III Scan refractive power/corneal analyzer system (NIDEK Co., Ltd., Gamagori, Japan). The parameters analyzed for a 4-mm pupil included the root mean square (RMS) of higher order aberrations (HOAs), RMS of the total spherical aberration, RMS of the total coma, and RMS of the total trefoil and point spread function (PSF), expressed as the Strehl ratio.

The IOL alignment meridian was calculated at the follow-up visits from the scanning device using the toric IOL summary map after pupillary mydriasis of at least $6 \mathrm{~mm}$ using tropicamide $1.0 \%$. At each visit, the same observer took three images of each patient. The device was defocused, realigned, and focused between each image. The final rotation was calculated as the mean of the rotation obtained in each of these three images. We have previously used this method for toric IOL alignment meridian calculation and showed its high repeatability. ${ }^{11}$

At the 4-month follow-up visit, astigmatic outcomes were calculated by vector analysis using the method described by Alpins. ${ }^{12,13}$ 


\begin{tabular}{|c|c|}
\hline \multicolumn{2}{|c|}{$\begin{array}{c}\text { TABLE } 1 \\
\text { Patient Demographics and } \\
\text { Clinical Information }\end{array}$} \\
\hline Parameter & Value \\
\hline Eyes $(n)$ & 51 \\
\hline Patients (n) & 39 \\
\hline Age $(y)$, mean \pm SD (range) & $70.8 \pm 9.7$ (53 to 89$)$ \\
\hline Male sex, n (\%) & $20(51)$ \\
\hline Right eyes, n (\%) & $25(48)$ \\
\hline $\begin{array}{l}\text { Axial length }(\mathrm{mm}) \text {, mean } \pm \\
\text { SD (range) }\end{array}$ & $24.05 \pm 1.83(21.08$ to 27.75$)$ \\
\hline $\begin{array}{l}\text { Corneal astigmatism (D), } \\
\text { mean } \pm \mathrm{SD} \text { (range) }\end{array}$ & $1.98 \pm 0.72(1.00$ to 4.50$)$ \\
\hline $\begin{array}{l}\text { IOL spherical equivalent } \\
\text { power (D), mean } \pm \text { SD } \\
\text { (range) }\end{array}$ & $18.92 \pm 4.82(8.75$ to 27.00$)$ \\
\hline $\begin{array}{l}\text { IOL cylinder power (D), mean } \\
\pm \text { SD (range) }\end{array}$ & $2.60 \pm 1.32(1.00$ to 6.00$)$ \\
\hline
\end{tabular}

\section{Statistical ANALYSIS}

All data were collected in an Excel database (Microsoft Office 2010; Microsoft Corporation, Redmond, WA). Statistics were done in accordance with the ICH statistical principles for clinical trials E9 guideline. All statistical analysis was performed using SPSS for Macintosh software (version 21.0; IBM Corporation, Armonk, NY). For all data samples, the normality of the distribution was checked using the Kolmogorov-Smirnov test. Whenever parametric analysis was possible, the Student's $t$ test for paired samples was used for preoperative and postoperative comparisons. When parametric analysis was not possible, differences between preoperative and postoperative data were evaluated with the Wilcoxon rank sum test. Results are expressed as mean \pm standard deviation. A $P$ value less than .05 was considered statistically significant.

\section{RESULTS}

This study included 51 eyes from 39 patients. The mean age was $70.8 \pm 9.7$ years (range: 53 to 89 years). No eyes were excluded from analysis due to intraoperative or postoperative complications. Patient demographics and preoperative clinical information are shown in Table 1. No patient was lost to follow-up.

\section{VISUAL ACUITY AND REFRACTION}

Table 2 shows the visual, refractive, and keratometric changes. Figure 1A shows the percentage of eyes with cumulative Snellen visual acuity $20 / x$ or better at the 4-month follow-up. There were no statistically significant differences in UDVA or CDVA across the examinations during the follow-up period. UDVA was $0.3 \operatorname{logMAR}$ or better (Snellen equivalent 20/40 or better) in 50 (98\%) eyes and 0.1 logMAR (Snellen equivalent 20/25 or better) in $42(82 \%)$ eyes. Figure 1B shows the attempted versus achieved SE refraction. Figure 1C shows the SE refractive accuracy. Postoperative SE refraction was within $\pm 0.50 \mathrm{D}$ of the attempted correction in 44 (86\%) eyes and within $\pm 1.00 \mathrm{D}$ in 50 (98\%) eyes. Figure 1D shows the distribution of postoperative refractive astigmatism. Refractive astigmatism was within $\pm 0.50 \mathrm{D}$ of the attempted correction in $30(59 \%)$ eyes and within $\pm 1.00 \mathrm{D}$ in all eyes. Figure 1E shows the target induced astigmatism (TIA) versus SIA. Undercorrection or overcorrection were independent on the magnitude of intended treatment. Figure 1F shows the refractive astigmatism angle of error. The majority of eyes $(61 \%)$ were within $-5^{\circ}$ to $5^{\circ}$ of the target.

\section{VECTOR ANALYSIS}

For vector analysis, data from manifest refraction in the postoperative period were compared with target data calculated from the preoperative keratometry. We calculated the geometric mean for the correction index. Mean magnitude of TIA, which represents the attempted astigmatic correction, was $1.96 \pm 0.94 \mathrm{D}$ (range: 0.70 to 4.50 D). Mean magnitude of SIA, which is the astigmatic correction achieved by surgery, was $1.85 \pm 1.01 \mathrm{D}$ (range: 0.07 to $4.64 \mathrm{D}$ ). Figure 2A shows the TIA vector and Figure 2B shows the SIA vector. Figure 2C shows the difference vector (vectorial difference between the TIA and SIA vectors). Figure 2D shows the correction index (SIA divided by TIA), which was $0.87 \mathrm{D}$ (range: 0.07 to 2.29 D), representing a slight undercorrection, confirmed by the magnitude of error (arithmetic difference between the TIA and the SIA), which was $-0.11 \pm 0.43 \mathrm{D}$ (range: -0.98 to $0.90 \mathrm{D}$ ). In eyes with treated against-the-rule astigmatism $\left(0^{\circ}\right.$ to $30^{\circ}$ and $150^{\circ}$ to $\left.180^{\circ}\right)$, the correction index was 0.94 , near the ideal value of 1 . When the treated astigmatism was with-the-rule $\left(60^{\circ}\right.$ to $\left.120^{\circ}\right)$, the correction index was 0.75 . In eyes with oblique astigmatism $\left(31^{\circ}\right.$ to $59^{\circ}$ and $121^{\circ}$ to $149^{\circ}$ ), the correction index was 0.73 , reflecting a slight undercorrection, although the number of treated eyes in this group was small (2) and all of the eyes had low astigmatism $(<1.50 \mathrm{D})$. The index of success, which is the difference vector divided by the TIA (ideally 0), was $0.33 \pm 0.27 \mathrm{D}$ (range: 0.00 to $1.43 \mathrm{D}$ ). The mean angle of error was $1.12^{\circ} \pm 9.82^{\circ}$ (range: $-19.89^{\circ}$ to $44^{\circ}$ ), representing a slight counterclockwise deviation from the intended correction axis. Mean absolute angle of error was $6.06^{\circ} \pm 7.81^{\circ}$ (range: $0^{\circ}$ to $44^{\circ}$ ).

\section{Rotational Stability}

At 4 months of follow-up, mean toric IOL axis rotation was $1.98^{\circ} \pm 1.78^{\circ}$ (range: $0^{\circ}$ to $7^{\circ}$ ). The difference 
TABLE 2

Visual Acuity, Refractive Results, and Keratometric Changes

\begin{tabular}{|c|c|c|c|}
\hline Parameter & Preoperative & 4 Months Postperative & $P$ \\
\hline \multicolumn{4}{|l|}{ Sphere (D) } \\
\hline Mean \pm SD & $-0.72 \pm 3.89$ & $0.07 \pm 0.37$ & $.244^{\mathrm{a}}$ \\
\hline Range & -10.00 to +8.00 & -0.75 to +1.00 & \\
\hline \multicolumn{4}{|c|}{ Refractive cylinder (D) } \\
\hline Mean \pm SD & $-2.38 \pm 1.17$ & $-0.51 \pm 0.29$ & $<.001^{a}$ \\
\hline Range & -6.00 to -0.50 & -1.00 to 0.00 & \\
\hline \multicolumn{4}{|l|}{ SE (D) } \\
\hline Mean \pm SD & $-1.91 \pm 3.85$ & $-0.19 \pm 0.38$ & $.004^{\mathrm{b}}$ \\
\hline Range & -10.50 to 6.75 & -1.13 to 0.50 & \\
\hline \multicolumn{4}{|l|}{ UDVA (logMAR) } \\
\hline Mean \pm SD & $1.02 \pm 0.63$ & $0.06 \pm 0.10$ & $<.001^{\mathrm{a}}$ \\
\hline Range & 0.22 to 3.00 & -0.18 to 0.40 & \\
\hline \multicolumn{4}{|l|}{ CDVA (logMAR) } \\
\hline Mean \pm SD & $0.52 \pm 0.49$ & $0.00 \pm 0.07$ & $<.001^{a}$ \\
\hline Range & 0.15 to 3.00 & -0.18 to 0.15 & \\
\hline \multicolumn{4}{|l|}{ Keratometry } \\
\hline \multicolumn{4}{|l|}{$\mathrm{K} 1$ (mm) } \\
\hline Mean \pm SD & $7.76 \pm 0.37$ & $7.79 \pm 0.34$ & $.103^{b}$ \\
\hline Range & 6.80 to 8.57 & 6.96 to 8.54 & \\
\hline \multicolumn{4}{|l|}{$\mathrm{K} 2(\mathrm{~mm})$} \\
\hline Mean \pm SD & $7.55 \pm 0.28$ & $7.58 \pm 0.31$ & $.161^{b}$ \\
\hline Range & 6.96 to 8.29 & 6.86 to 8.28 & \\
\hline
\end{tabular}

between 1-day and 4-month follow-up was not statistically significant $(P=.789)$. No eye required secondary surgery for IOL rotation.

\section{Ocular AberRometry}

Table 3 shows the ocular aberrometry outcomes through the mean wavefront aberration values and the Strehl ratio at the 4-month follow-up.

\section{DISCUSSION}

In our prospective case series, implantation of the Precizon Toric IOL resulted in a significant improvement in UDVA and CDVA, with $98 \%$ of eyes achieving a UDVA of $0.3 \log$ MAR or better. For SE IOL power calculation, we used the SRK/T formula ${ }^{10}$ in eyes with an axial length greater than $22 \mathrm{~mm}$ and the Hoffer Q formula ${ }^{9}$ in eyes with an axial length of $22 \mathrm{~mm}$ or less. This choice was accurate enough to achieve a postoperative SE near the target $(-0.18 \pm 0.38 \mathrm{D})$. Refractive cylinder was within \pm 1.00 $\mathrm{D}$ in all eyes and remained stable throughout the follow- up. These visual and refractive outcomes are consistent with recent studies of other toric IOLs. ${ }^{5-7,14}$

Rotational stability is paramount in a toric IOL. Even minor degrees of misalignment can cause significant loss of cylinder correction efficacy with subsequent residual refractive errors and visual acuity deterioration. ${ }^{15}$ The postoperative rotational stability in our study was excellent, with a mean rotation at the 4-month followup of $1.98^{\circ} \pm 1.78^{\circ}$. These rotational stability results are similar to those reported in other recent toric IOL studies. ${ }^{5-7,14}$ IOL rotation is mainly caused by haptic compression resulting from capsular contraction. The Precizon Toric IOL was designed with offset-shaped haptics to prevent postoperative rotation and posterior capsule opacification. The IOL biomaterial is crucial to its rotational stability. IOL optic surface adhesiveness varies with the IOL material, being higher with acrylic IOLs, followed by polymethylmethacrylate IOLs and silicone IOLs. ${ }^{16}$ The study IOL is made of hydrophilic acrylate, which should ensure a strong capsular bag ad- 


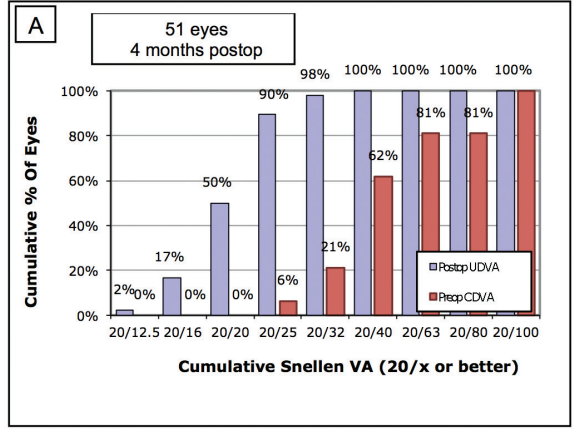

Uncorrected Distance Visual Acuity

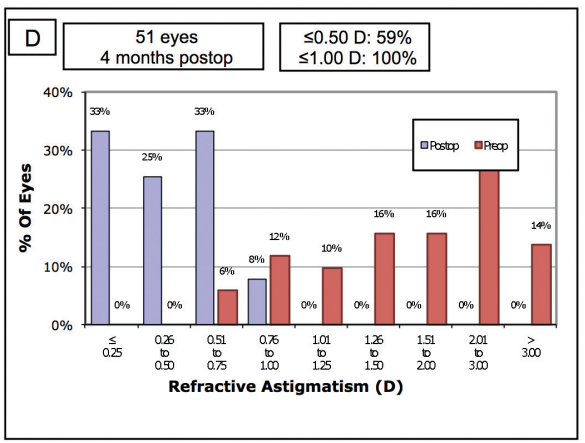

Refractive Astigmatism

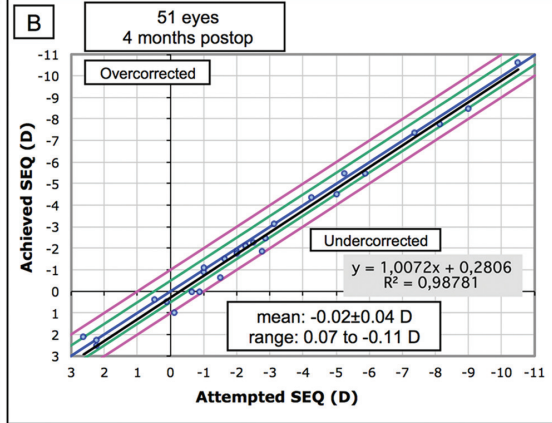

Spherical Equivalent Refraction Attempted vs Achieved

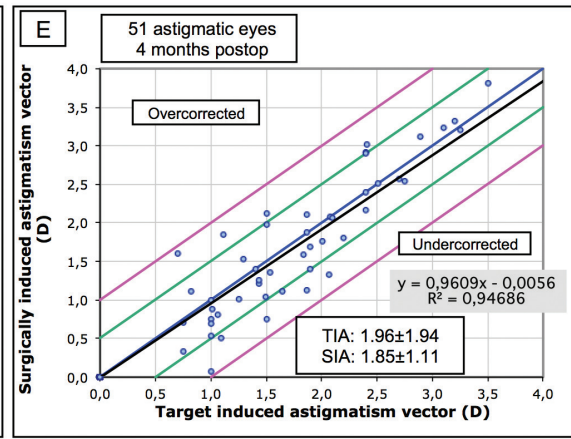

Target Induced Astigmatism vs
Surgically Induced Astigmatism

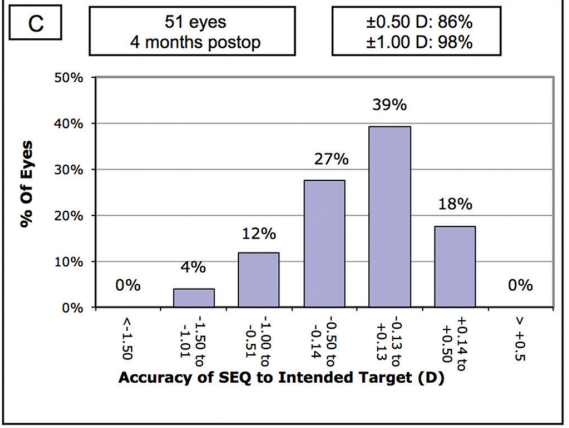

Spherical Equivalent Refraction Accuracy

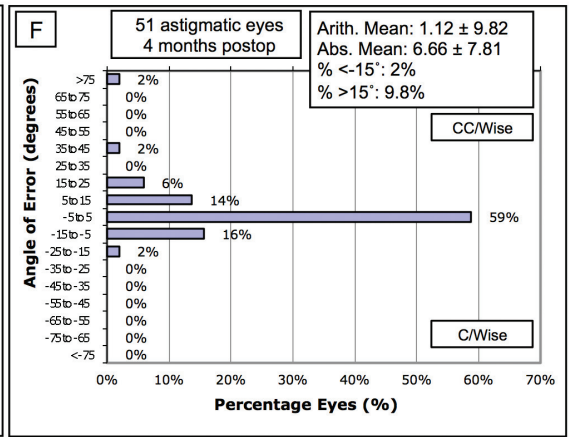

Refractive Astigmatism Angle of Error

Figure 1. Postoperative results at the 4-month follow-up. (A) Percentage of eyes with cumulative Snellen visual acuity 20/x or better. (B) Attempted versus achieved spherical equivalent refraction (SEQ). (C) Accuracy of SEQ correction. (D) Distribution of refractive astigmatism. (E) Target induced astigmatism (TIA) versus surgically induced astigmatism (SIA). (F) Refractive astigmatism angle of error. UDVA = uncorrected distance visual acuity; CDVA $=$ corrected distance visual acuity; $\mathrm{D}=$ diopters

hesion. It is known that $1^{\circ}$ of off-axis rotation results in a loss of approximately $3.3 \%$ of the IOL's cylinder power. ${ }^{15}$ The Precizon Toric IOL is designed with a broader toric meridian and is more tolerant of misalignment. Using intraoperative aberrometry, Mertens ${ }^{17}$ showed that the new design of the Precizon Toric IOL decreases loss of cylinder power with misalignment in $50 \%$ when compared with a traditional toric IOL design (Lentis toric IOL; Oculentis GmbH, Berlin, Germany) ${ }^{17}$; therefore, considering these data and our misalignment results, only approximately $3.2 \%$ of the IOL cylinder power was lost in our eyes. There was a significant difference between postoperative IOL rotation and absolute angle of error $(P<.001$; Wilcoxon test) and there was no correlation between rotation and angle of error (Spearman's rho $=.271 ; P=.055$ ), suggesting IOL rotation was not an important factor in the small angle of error we observed. There are several methods to determine the misalignment of a toric IOL. One simple method is to perform a slit-lamp examination with the pupil dilated, although this can be rather inaccurate because the measuring reticule on the slit-lamp uses $5^{\circ}$ steps. Analysis of intraoperative and postoperative retroillumination photographs is an effective method of determining IOL rotation..$^{18}$ It is also possible to calculate misalignment by vector analysis, measuring the angle of error. ${ }^{19} \mathrm{We}$ used the OPD-III Scan, which is a simple and repeatable method of studying IOL misalignment by retroillumination photographs. ${ }^{11}$

In our study, TIA was higher than SIA, so a slight undercorrection was achieved. Similarly, the correction index (ratio of SIA to TIA) was 0.87 and the difference vector was 0.18 , reflecting the slight undercorrection achieved by the toric IOL implantation. When the treated astigmatism was with-the-rule, the correction index was 0.75 , reflecting a slight undercorrection. In eyes with treated against-the-rule astigmatism, the correction index was 0.94 , almost the ideal value of 1 . In eyes with oblique astigmatism, the correction index was 0.73 , reflecting only a slight undercorrection considering the low astigmatism magnitude in eyes in this group.

For analysis of aggregate data of astigmatism, Alpins described two methods: an examination based in arithmetic means, disregarding the orientation of the vector to determine the mean vector magnitude, or the addition of the magnitudes of the vectors with regard to 

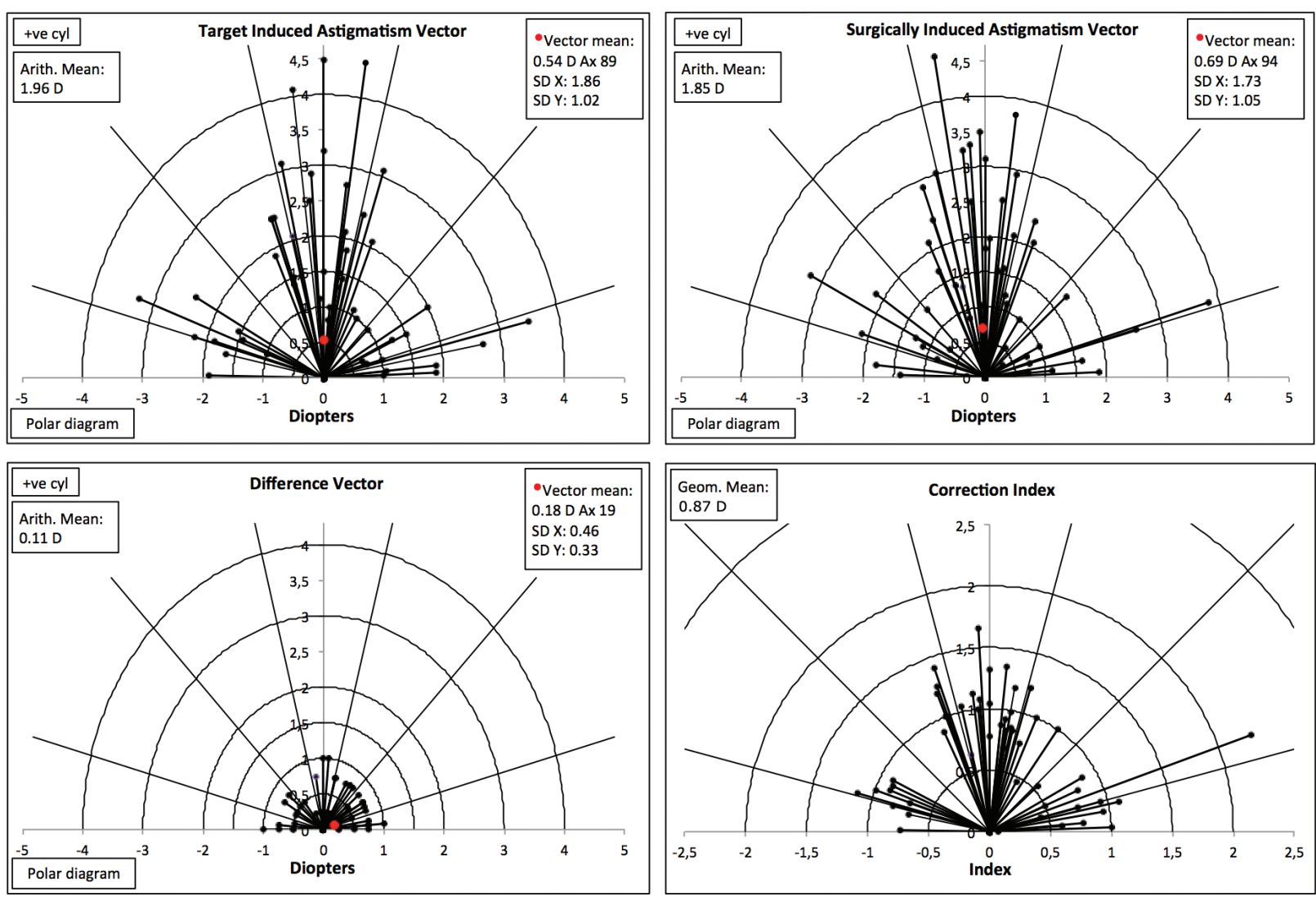

Figure 2. Single-angle polar plots for the target induced astigmatism vector (TIA), surgically induced astigmatism vector (SIA), difference vector (DV), and correction index $(\mathrm{Cl})$. The vector means are plotted as a red dot (calculated in double-angle vector space) and the standard deviations (SDs) for the $\mathrm{X}$ and $\mathrm{Y}$ directions are displayed in the call-out box. $\mathrm{D}=$ diopters

each vector's orientation to determine a summated vector mean of the group. We used the first method in our study. The summated vector mean is always less than the mean vector magnitude (in our case, TIA $=0.54$, SIA $=0.69$, and difference vector $=0.18$ ). When the difference between the two methods is high, as in our case, the changes are more likely due to random events. ${ }^{13} \mathrm{Al}$ though the undercorrection in our study was small and probably due to the intrinsic variation of techniques to measure astigmatism, it can have several other possible explanations. As reported by Goggin et al., there may be an underestimation of the effective cylinder power at the corneal plane by the manufacturer. ${ }^{20}$ Another possible explanation is the high number of eyes in our study with preoperative against-the-rule astigmatism. In these eyes, an underestimation of corneal astigmatism results from ignoring the negative power effect of the steep meridian of the posterior cornea, which tends to be aligned vertically. ${ }^{21}$ Previous studies of toric IOLs including vector analysis reported either overcorrection ${ }^{7,22}$ or undercorrection. ${ }^{23,24}$

In our study, the HOA RMS, coma, trefoil, and Strehl ratio were similar to those found in recent studies of oth-
TABLE 3

\section{Ocular Aberrometry Analysis}

\begin{tabular}{ll}
\hline Parameter & Value \\
\hline HOA RMS $(\mu \mathrm{m})$ & $0.33 \pm 0.13$ \\
Mean \pm SD & 0.12 to 0.93 \\
Range & \\
Spherical aberration $(\mu \mathrm{m})$ & $0.21 \pm 0.07$ \\
Mean \pm SD & 0.01 to 0.30 \\
Range & \\
Coma $(\mu \mathrm{m})$ & $0.24 \pm 0.16$ \\
$\quad$ Mean \pm SD & 0.06 to 0.69 \\
Range & \\
Trefoil $(\mu \mathrm{m})$ & $0.32 \pm 0.19$ \\
Mean $\pm \mathrm{SD}$ & 0.13 to 0.90 \\
Range & \\
Strehl ratio & $0.03 \pm 0.02$ \\
Mean $\pm \mathrm{SD}$ & 0.00 to 0.07 \\
Range &
\end{tabular}

HOA RMS = higher order aberration root mean square; $S D=$ standard deviation 
er toric IOLs. ${ }^{11,25}$ Postoperative spherical aberration (0.21 $\pm 0.07 \mu \mathrm{m}$ ) reflects the $0 \mu \mathrm{m}$ of spherical aberration in the aspheric optic of the Precizon Toric IOL. Ocular HOAs were evaluated with the OPD-III Scan. This system has good repeatability for the wavefront measurement of total, corneal, and internal optical aberrations. ${ }^{12,26}$

The results of our study show that the implantation of the Precizon Toric IOL in patients with cataract and regular corneal astigmatism provided excellent visual outcomes, predictability of astigmatic correction, optical quality, and rotational stability.

\section{AUTHOR CONTRIBUTIONS}

Study concept and design (TBF, FJR); data collection (TBF, FJR); analysis and interpretation of data (TBF, FJR, TTJMB); writing the manuscript (TBF); critical revision of the manuscript (TBF, FJR, TTJMB); statistical expertise (TBF); supervision (TBF, FJR, TTJMB)

\section{REFERENCES}

1. Hoffmann PC, Hütz WW. Analysis of biometry and prevalence data for corneal astigmatism in 23,239 eyes. J Cataract Refract Surg. 2010;36:1479-1485.

2. Ferrer-Blasco T, Montés-Micó R, Peixoto-de-Matos SC, GonzálezMéijome JM, Cerviño A. Prevalence of corneal astigmatism before cataract surgery. J Cataract Refract Surg. 2009;35:70-75.

3. Hoffer KJ. Biometry of 7,500 cataractous eyes. Am J Ophthalmol. 1980;90:360-368.

4. Villegas EA, Alcon E, Artal P. Minimum amount of astigmatism that should be corrected. J Cataract Refract Surg. 2014;40:13-19.

5. Nagamoto T, Eguchi G. Effect of intraocular lens design on migration of lens epithelial cells onto the posterior capsule. $J$ Cataract Refract Surg. 1997;23:866-872.

6. Lombardo M, Carbone G, Lombardo G, De Santo MP, Barberi R. Analysis of intraocular lens surface adhesiveness by atomic force microscopy. J Cataract Refract Surg. 2009;35:1266-1272.

7. Hansen SO, Solomon KD, McKnight GT, et al. Posterior capsular opacification and intraocular lens decentration: Part I. Comparison of various posterior chamber lens designs implanted in the rabbit model. J Cataract Refract Surg. 1988;14:605-613.

8. Kohnen T, Klaproth OK, Bühren J. Effect of intraocular lens asphericity on quality of vision after cataract removal: an intraindividual comparison. Ophthalmology. 2009;116:1697-1706.

9. Hoffer KJ. The Hoffer Q formula: a comparison of theoretic and regression formulas. J Cataract Refract Surg. 1993;19:700-712.

10. Retzlaff JA, Sanders DR, Kraff MC. Development of the SRK/T intraocular lens implant power calculation formula. J Cataract Refract Surg. 1990;16:333-340. Erratum: J Cataract Refract Surg. 1990;16:528.

11. Ferreira TB, Marques EF, Rodrigues A, Montés-Micó R. Visual and optical outcomes of a diffractive multifocal toric intraocular lens. J Cataract Refract Surg. 2013;39:1029-1035.

12. Alpins NA. A new method of analyzing vectors for changes in astigmatism. J Cataract Refract Surg. 1993;19:524-533.

13. Alpins NA. Astigmatism analysis by the Alpins method. J Cataract Refract Surg. 2001;27:31-49.

14. Krall EM, Arlt EM, Hohensinn M, et al. Vector analysis of astigmatism correction after toric intraocular lens implantation. J Cataract Refract Surg. 2015;41:790-799.

15. Shimizu K, Misawa A, Suzuki Y. Toric intraocular lenses: correcting astigmatism while controlling axis shift. J Cataract Refract Surg. 1994;20:523-526.

16. Oshika T, Nagata T, Ishii Y. Adhesion of lens capsule to intraocular lenses of polymethylmethacrylate, silicone, and acrylic foldable materials: an experimental study. Br J Ophthalmol. 1998;82:549-553.

17. Mertens EL. Evaluation of a new toric IOL optic by means of intraoperative wavefront aberrometry (ORA system): the effect of IOL misalignment on cylinder reduction. Presented at: XXXII Congress of the ESCRS; September 13-17, 2014; London, United Kingdom.

18. Becker KA, Auffarth GU, Völcker HE. Measurement method for the determination of rotation and decentration of intraocular lenses [article in German]. Ophthalmologe. 2004;101:600-603.

19. Rho CR, Joo CK. Effects of steep meridian incision on corneal astigmatism in phacoemulsification cataract surgery. J Cataract Refract Surg. 2012;38:666-671.

20. Goggin M, Moore S, Esterman A. Outcome of toric intraocular lens implantation after adjusting for anterior chamber depth and intraocular lens sphere equivalent power effects. Arch Ophthalmol. 2011;129:998-1003. Erratum in: Arch Ophthalmol. 2011;129:1494.

21. Goggin M, Zamora-Alejo K, Esterman A, van Zyl L. Adjustment of anterior corneal astigmatism values to incorporate the likely effect of posterior corneal curvature for toric intraocular lens calculation. J Refract Surg. 2015;31:98-102.

22. Alió JL, Piñero DP, Tomás J, Plaza AB. Vector analysis of astigmatic changes after cataract surgery with implantation of a new toric multifocal intraocular lens. J Cataract Refract Surg. 2011;37:1217-1229.

23. Alió JL, Piñero DP, Tomás J, Alesón A. Vector analysis of astigmatic changes after cataract surgery with toric intraocular lens implantation. J Cataract Refract Surg. 2011;37:1038-1049.

24. Visser N, Berendschot TT, Bauer NJ, Nuijts RM. Vector analysis of corneal and refractive astigmatism changes following toric pseudophakic and toric phakic IOL implantation. Invest Ophthalmol Vis Sci. 2012;53:1865-1873.

25. Ferreira TB, Almeida A. Comparison of the visual outcomes and OPD-scan results of AMO Tecnis toric and Alcon Acrysof IQ toric intraocular lenses. J Refract Surg. 2012;28:551-555.

26. Rozema JJ, Van Dyck DEM, Tassignon M-J. Clinical comparison of 6 aberrometers: Part 2. Statistical comparison in a test group. J Cataract Refract Surg. 2006;32:33-44. 


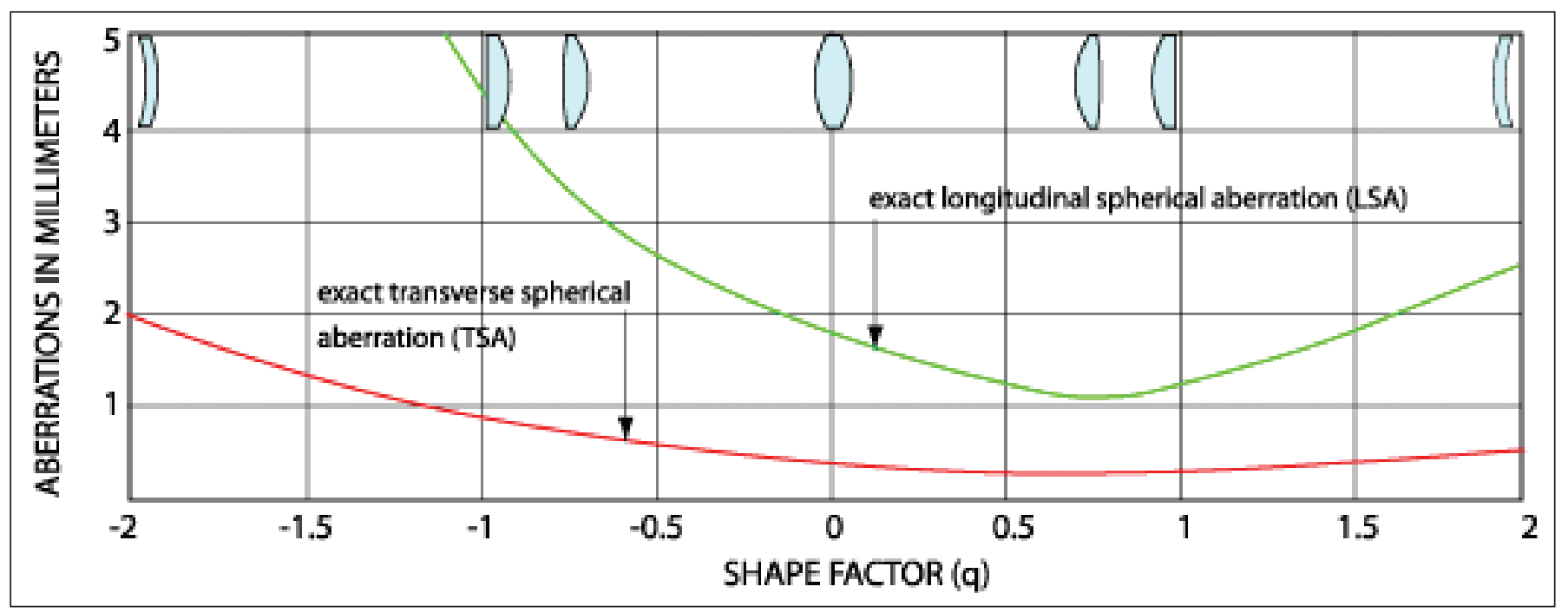

Figure A. Relationship of Coddington shape factor with spherical aberration. Image available open access from Melles Griot (www.cvilaseroptics.com).

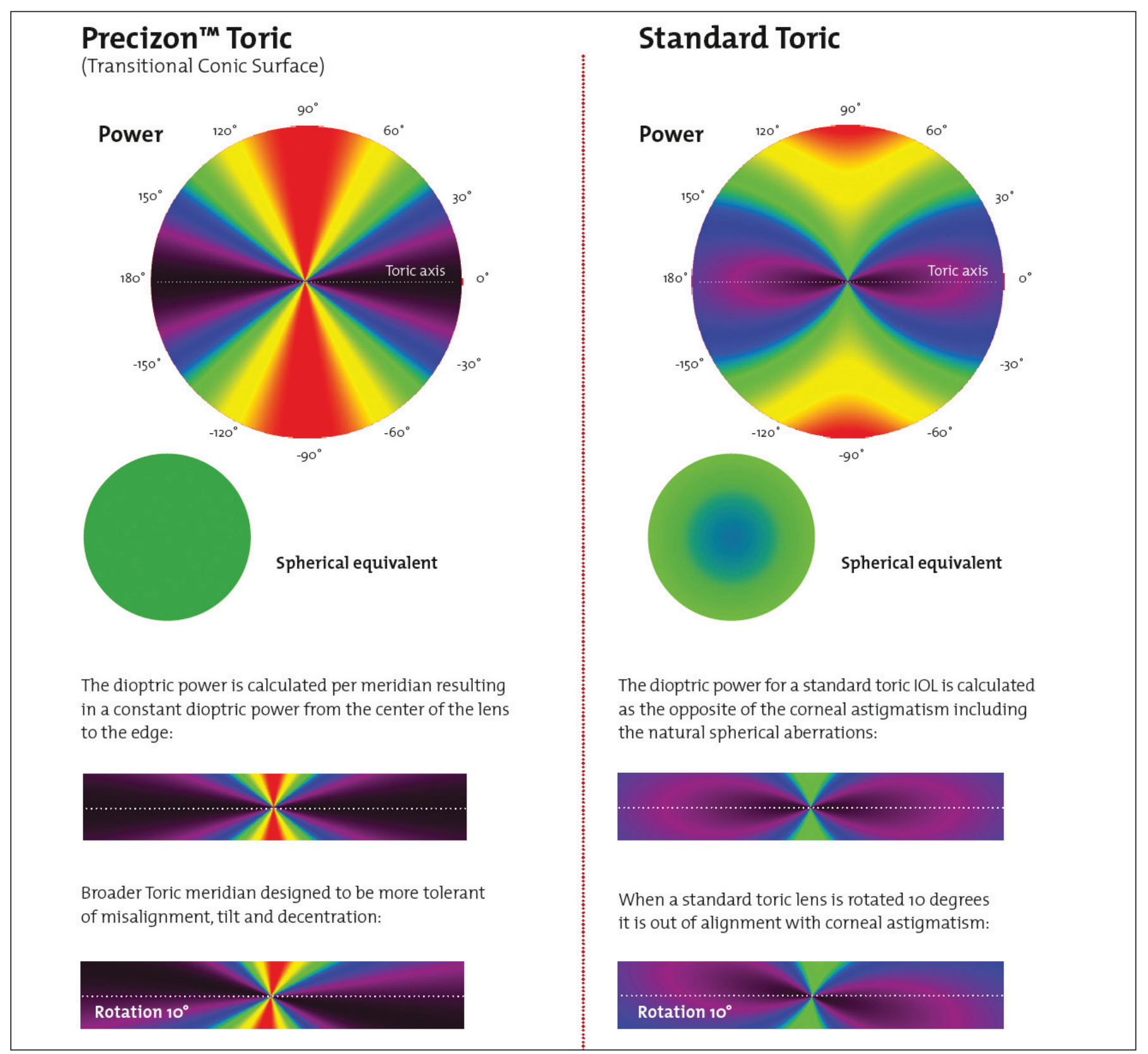

Figure B. The transitional conic surface of the Precizon Toric IOL (model 565; Ophtec BV, Groningen, The Netherlands). 